\title{
LETTERS
}

\section{Insurance helps to brush physician depression under the rug}

I found Roger Collier's article on physician suicide $^{1}$ to be both timely and important.

Groups that are meant to support physicians can also deter them from seeking care. For example, insurance provided by the Ontario Medical Association, which is used by many physicians both inside and outside of Ontario, denies insurance coverage for counselling and medication if an insured member has a history of mental health concerns. To be covered, a physician with such a history has to seek a letter stating that she or he has been stable and has not required treatment for at least two years. Of course, physicians with a history of mental health problems who are looking for help are unlikely to be free from mental health concerns at that moment.

If insurance provided by a medical association denies physicians coverage for the care they need, calling it a pre-existing condition, how can we even pretend to be taking physician mental health seriously?

\section{Sarah M. Giles MD}

Locum family and emergency physician

- Cite as: CMAJ 2018 February 26;190:E227. doi: $10.1503 / \mathrm{cmaj} .68615$

\section{Reference}

1. Collier R. Physician suicide too often "brushed under the rug." CMAJ 2017;189 E1240-1.

Competing Interests: None declared. 